University of Nebraska - Lincoln

DigitalCommons@University of Nebraska - Lincoln

Gordon Gallup Publications

Research Papers in Physics and Astronomy

June 1952

\title{
Hydrogen Bond Energies in Carboxylic Acids
}

M.M. Jones

Bailey Chemical Laboratory, University of Kansas, Lawrence, Kansas

W.R. Gilkerson

Bailey Chemical Laboratory, University of Kansas, Lawrence, Kansas

Gordon A. Gallup

UNL,ggallup1@unl.edu

Follow this and additional works at: https://digitalcommons.unl.edu/physicsgallup

Part of the Physics Commons

Jones, M.M.; Gilkerson, W.R.; and Gallup, Gordon A., "Hydrogen Bond Energies in Carboxylic Acids" (1952). Gordon Gallup Publications. 30.

https://digitalcommons.unl.edu/physicsgallup/30

This Article is brought to you for free and open access by the Research Papers in Physics and Astronomy at DigitalCommons@University of Nebraska - Lincoln. It has been accepted for inclusion in Gordon Gallup Publications by an authorized administrator of DigitalCommons@University of Nebraska - Lincoln. 
cyclopropane, ethylene oxide, and propylene oxide have been reported in the literature. Accordingly, we have studied these compounds using the Quincke method previously described. ${ }^{3}$ The materials were obtained from commercial sources and purified by a careful distillation in a Hypercal Podbielniak column. The results are given in Table $\mathbf{I}$. For comparison the susceptibilities of the corresponding straight chain isomers as reported in the literature are also included in the table.

The molar diamagnetic susceptibilities for these compounds are unusually large, being about 8.6 units greater than the corresponding straight-chain isomer. The susceptibility for cyclopropane is considerably greater than the value of $-31.7 \times 10^{-6}$ calculated from Pascal's increments; ${ }^{1}$ while Farquharson and Sastri's data ${ }^{2}$ permit a calculated value of $-30.8 \times 10^{-6}$. The present data are however, consistent with the chemical and spectroscopic properties of ethylene oxide and cyclopropane. Walsh ${ }^{4}$ has suggested that these compounds contain carbon atoms having trigonal wave functions. If such is the case, the compounds will be magnetically anisotropic. Some of the electrons will be able to precess about the plane of the ring making the susceptibility considerably greater than that of the corresponding straight chain isomer. The effect of $p_{z}$ electrons on the susceptibilities of aromatic compounds has been discussed by Pauling ${ }^{5}$ and Lonsdale. ${ }^{6}$ If we assume that cyclopropane has three trigonal carbon atoms with atomic susceptibilities of $-(3 / 4) 6 \times 10^{-6}$ and that each hydrogen atom contributes $-2.9 \times 10^{-6}$, then the anisotropy may be calculated to be -27 $\times 10^{-6}$. In order to account for this, the three $p_{z}$ electrons must precess in a ring having a radius of $1.46 \mathrm{~A}$. In cyclopropane a carbon nucleus is about $0.7 \mathrm{~A}$ from the center of the triangle; in addition the radius of the orbitals of the valence electrons is approximately $0.7 \mathrm{~A}$. Their sum is close to the calculated radius of $1.46 \mathrm{~A}$.

In the case of ethylene and propylene oxide one may calculate an anisotropy of $-19.8 \times 10^{-6}$ if one takes the contribution of the bridge oxygen to be $-(3 / 4) 4.6 \times 10^{-6}$. The effective radius of precession of the $p_{z}$ electrons becomes $1.25 \mathrm{~A}$, which is somewhat less than shown by cyclopropane.

* This work was supported by the ONR, contract N6-onr-231, Task Order VI, project No. NR-056-105.

1 P. Pascal, Comp. rend. 181, 656 (1925)

2 J. Farquharson and M. Sastri, Trans. Faraday Soc. 33, 1474 (1937).

8 Lacher, Scruby, and Park, J. Am. Chem. Soc. 71, 1797 (1949)

4 A. D. Walsh, Trans. Faraday Soc. 45, 179 (1948)

- K. Lonsdale, Proc. Roy. Soc. (London) 159A, 149 (1937).

\section{Hydrogen Bond Energies in Carboxylic Acids}

M. M. Jones,* W. R. Gilkerson,† and G. A. Gallup $\dagger$

Bailey Chemical Laboratory, Universily of Kansas, Lawrence, Kansas (Received April 14, 1952)

$\mathrm{T}$

$\mathrm{HE}$ heat of dissociation of carboxylic acid dimers in the vapor phase may be calculated from a consideration of the van der Waals interaction energy. Account is taken of the orientation, induced dipole, and dispersion interactions between the carbonyl and hydroxyl bonds, as well as cross terms.

A number of approximations were necessary in order that the complexity of the calculation not be greater than its importance merits. These are (a) that the carbonyl and hydroxyl bonds may be considered as classical dipoles with spherically symmetrical polarizability; (b) that the elementary units of bond interaction are additive; (c) the relative orientation and bond distances in the two acid molecules remain constant throughout the association process and are those found experimentally in the formic acid dimer; (d) the principal contributors to such interaction are the carbonyl and hydroxyl bonds. Since we have used London's simplified dispersion relation, all of the assumptions inherent in its derivation are included.

The process considered is the approach of two acid molecules from an infinite separation, to form the dimer configuration given by Pauling ${ }^{\mathbf{l}}$ for formic acid. The interaction energy relations used were the following:

$$
\begin{array}{ll}
\text { orientation; } & U_{0}=-2 \frac{\mu_{1} \mu_{2}}{r^{3}} \cos \vartheta_{1} \cos \vartheta_{2} \\
\text { induction; } & U_{I}=-\frac{\mu_{1}^{2} \alpha_{2}}{2 r^{6}}\left(1+3 \cos ^{2} \vartheta_{1}\right) \\
\text { dispersion; } & U_{D}=-\frac{3 \alpha_{1} \alpha_{2}}{2 r^{6}} \frac{J_{1} J_{2}}{J_{1}+J_{2}}
\end{array}
$$

where $\mu$ is the bond moment, ${ }^{2} \alpha$ its polarizability, ${ }^{3} r$ the distance between bond centers, and $J$ the bond ionization energy. ${ }^{4}$

The calculated heat of dimerization is $15.9 \mathrm{kcal}$, while the measured values are 14.1 and $16.4 \mathrm{kcal}$ for formic ${ }^{5}$ and acetic acids, respectively. It may be concluded that, to a fairly good approximation, the "hydrogen bond" in carboxylic acids may be accounted for on the basis of intermolecular forces operating over a longer range than that usually ascribed to bonding forces. The validity of the type of calculation made here has been critically discussed by London, ${ }^{7}$ but he seemed principally concerned with applications to extended conjugated systems, of which ours is not an example.

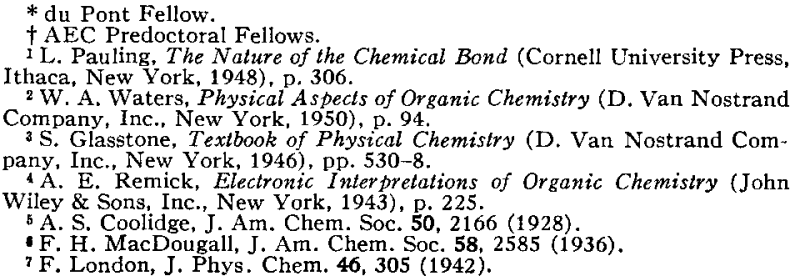

\section{Carbon-Oxygen Exchange in Chemisorbed Carbon Monoxide}

R. P. EIschens and A. N. WebB

Beacon Laboratories of The Texas Company, Beacon, New York (Received April 7,1952 )

A QUESTION of interest to the study of the chemisorption $A$ of carbon monoxide on iron is whether the carbon is desorbed with the same oxygen to which it was bonded prior to the adsorption. A mixture of ${ }^{13} \mathrm{O}$ and $\mathrm{CO}^{18}$ was chemisorbed on iron and then desorbed. The presence of $\mathrm{C}^{13} \mathrm{O}^{18}$ in the desorbed gas in amounts greater than expected from normal abundance ratios shows that an intermolecular oxygen exchange occurs.

The $\mathrm{C}^{13} \mathrm{O}$ was prepared by reduction over zinc at $425^{\circ} \mathrm{C}^{1}$ of $\mathrm{C}^{13} \mathrm{O}_{2}$ obtained by the addition of perchloric acid to $\mathrm{BaC}^{13} \mathrm{O}_{3}{ }^{2}$ The $\mathrm{CO}^{18}$ was obtained from the Research Institute of Temple University.

The designation $\mathrm{C}^{13} \mathrm{O}$ as used here refers to carbon monoxide in which the $\mathrm{C}^{13}$ abundance has been enriched to 37.9 percent and $\mathrm{CO}^{18}$ refers to carbon monoxide in which the $\mathrm{O}^{18}$ abundance has been enriched to 14.4 percent. The $\mathrm{C}^{13}$ abundance in $\mathrm{CO}^{18}$ and the $\mathrm{O}^{18}$ abundance in the $\mathrm{C}^{13} \mathrm{O}$ are normal.

The analysis of the $\mathrm{C}^{13} \mathrm{O}$ and $\mathrm{CO}^{18}$ are shown in Table $\mathrm{I}^{3}$

The $\mathrm{O}^{18}$ abundance in the $\mathrm{CO}_{2}$ is the same as in the $\mathrm{CO}^{18}$; however, the $\mathrm{O}^{18}$ abundance in the oxygen is normal.

The iron was prepared by reduction of $\mathrm{Fe}_{2} \mathrm{O}_{3}$ with purifed hydrogen for 6 days at $400^{\circ} \mathrm{C}$. The $\mathrm{Fe}_{2} \mathrm{O}_{3}$ was prepared from the nitrate by conventional precipitation methods.

The volume of nitrogen in the BET monolayer was $89 \mathrm{cc}$ for the $91.1 \mathrm{~g}$ sample. The reduction was resumed after the BET determination and continued for an additional 8 days. After the reduction the sample was pumped at $400^{\circ} \mathrm{C}$ for 2 hours at a pressure of $1 \times 10^{-5} \mathrm{~mm}$ to remove the hydrogen.

It was assumed that the iron would chemisorb $91.5 \mathrm{cc}$ of carbon monoxide. A mixture of $39.6 \mathrm{cc}$ of $\mathrm{C}^{13} \mathrm{O}$ and $57.9 \mathrm{cc}$ of $\mathrm{CO}^{18}$ was admitted to the iron at $-78^{\circ} \mathrm{C}$. Only $75.7 \mathrm{cc}$ were rapidly adsorbed. The remaining $15.8 \mathrm{cc}$ were pumped off with a hand oper- 
ated Taepler pump. The chemisorbed carbon monoxide was pumped off with a combination mercury diffusion-Sprengler pump. ${ }^{4}$ When the rate of pumping at a specified temperature appeared to be negligible, the temperature was increased. The carbon monoxide collected at each temperature was kept separate and analyzed.

TABLE I.

\begin{tabular}{lcc}
\hline & $\mathrm{C}^{13} \mathrm{O}$ & $\mathrm{CO}^{18}$ \\
\hline Total carbon monoxide & 99.7 & 90.6 \\
Nitrogen & $\ldots$. & 1.6 \\
Oxygen & $\ldots$. & 0.4 \\
Carbon dioxide & 0.1 & 6.0 \\
Hydrogen & 0.2 & 1.4 \\
Methane & \\
\hline
\end{tabular}

The amount of $\mathrm{C}^{13} \mathrm{O}^{18}$ present at equilibrium was calculated to be 1.4 percent. There is a theoretical blank of 0.1 percent due to the natural abundance of $\mathrm{C}^{13}$ and $\mathrm{O}^{18}$. This was confirmed by an experimental blank of 0.1 which was obtained with a sample of the gas mixture which had been exposed to the hot mercury encountered in the gas collecting pump.

The results of the experiment are given in Table II. Here are recorded the temperature at which the carbon monoxide was

TABLE II.

\begin{tabular}{cccc}
\hline Temp. ${ }^{\circ} \mathrm{C}$ & Volume & Time & $\mathrm{C}^{13018}$ \\
\hline Unadsorbed & 15.8 & 0 & $\ldots$ \\
-78 & 13.7 & 28 & $\cdots$ \\
-33 & 12.5 & 118 & 0.3 \\
0 & 16.1 & 164 & 0.4 \\
25 & 14.4 & 236 & 0.6 \\
60 & 12.2 & 284 & $\cdots$ \\
$120-160$ & 4.9 & 336 & 1.3 \\
Loss & 1.9 & $\cdots$ & \\
\hline
\end{tabular}

pumped off, the volume of the batch in cc stp, the accumulated pumping time in hours, and the percentage of the carbon monoxide which is $\mathrm{C}^{13} \mathrm{O}^{18}$.

The mass spectrometer analyses of the $\mathrm{C}^{13} \mathrm{O}^{18}$ ratio are accurate to 5 percent of the reported value in the $0.1-0.3$ percent range.

The $\mathrm{C}^{13} \mathrm{O}^{18}$ analyses for the nonadsorbed gas and the batches collected at -78 and $0^{\circ} \mathrm{C}$ were not successful because the sample bulbs leaked prior to the mass spectrometer determination. This lowered the total carbon monoxide concentration to levels so low that the isotopic composition could not be accurately measured.

The batch collected at $120-160^{\circ} \mathrm{C}$ is unusual in that about half of the $4.9 \mathrm{cc}$ is carbon dioxide. This carbon dioxide is in isotopic equilibrium with the carbon monoxide.

These data show that significant oxygen exchange occurs at temperatures as low as $-33^{\circ} \mathrm{C}$, and equilibrium is almost attained within a reasonable time at $120-160^{\circ} \mathrm{C}$.

The exchange could be explained by postulating a mechanism which involves an intermediate complex. In the complex a single carbon is attached to two oxygens and can be desorbed with either one. A second mechanism in which the carbon-oxygen bond is ruptured so that atomic species of oxygen and carbon exist on the surface could also be postulated. The data are not sufficient to distinguish between these two mechanisms.

Further work is being done on this problem. The direction of this work is toward the use of purer $\mathrm{CO}^{18}$ and study of the exchange at temperatures lower than $-33^{\circ} \mathrm{C}$.

We are grateful to Dr. L. C. Roess for his interest and cooperation in this work.

1 R. B. Bernstein and T. I. Taylor, Science 106, 498 (1948).

2 The $\mathrm{BaC}^{3} \mathrm{O}$ was obtained from the AEC.

2 The $\mathrm{BaC}^{13} \mathrm{O}_{3}$ was obtained from the $\mathrm{AEC}$. All of analyses reported here were determined with a Consolidated
Engineering Type 21-101 mass spectrometer. The analyses were carried Engineering Type $21-101$ mass spectrometer. The analyses

out by M. S. Donovan under the supervision of . H. Shively.

\section{Experimental Efforts to Find Radioactivity Induced by the Firing of Shaped Charges}

G. J. Plain, J. C. Mclaughlin, and F. K. Odencrantz U. S. Naval Ordnance Test Station, Inyokern, China Lake, California

(Received March 31, 1952)

7 VIDENCES of nuclear transmutations produced by the 1 detonation of shaped charges have been reported. ${ }^{1}$ It was reported that when splinters of silver, copper, zinc, and iron from plates of these metals which had been subjected to shaped charges were exposed to a Geiger-Mueller counter an increase in radioactivity was indicated. Especially in the case of silver there was reported a strong indication that owing to the explosion the isotope $\mathrm{Ag}^{108}$ had been formed.

In order to form $\mathrm{Ag}^{108}$ from ordinary silver either of these two reactions might be feasible, the addition of a neutron to $\mathrm{Ag}^{107}$, or the emission of a neutron from $\mathrm{Ag}^{109}$; the second of these appears highly improbable. From a consideration of the temperature and particle velocities ${ }^{2}$ involved in the detonation, the possibility of nuclear transmutations leading to such radioactive isotopes seems extremely unlikely. A proton or neutron, having a velocity of $100,000 \mathrm{ft} / \mathrm{sec}$, which appears to be a conservative upper limit of velocity of the particles in the gas stream, has an energy of only 5 electron volts, and we are aware of no mechanism for neutron production at these low energies. On the other hand, thermonuclear processes seem insufficiently prolific, for the contribution of the thermal velocity at a temperature of $20,000^{\circ} \mathrm{K}$ would be approximately only $70,000 \mathrm{ft} / \mathrm{sec}$. The stream velocity and temperature could be assumed to be considerably higher without increasing the energy by an order of magnitude.

In an investigation of this effect, nine shaped charges ${ }^{3}$ have been fired into targets of brass, aluminum, silver, zinc, and lithium. Three of the charges were 2 inches in diameter of Composition C, with $\frac{1}{8}$-inch brass liners and cone angles of 60 degrees. Two of these were fired into silver targets and one into a brass target from stand-off distances of 6 inches. Three of the charges were 6 inches in diameter, contained 25 pounds of Composition C-3, had $\frac{1}{4}$-inch steel liners and 60-degree cone angles. One of these was fired into an aluminum target from a stand-off distance of 12 inches, one was fired into a zinc target, and the third was fired into a lithium target, the latter two from stand-off distances of 2 feet. The remaining three charges were 4 inches in diameter, of Composition $\mathrm{C}-3$, with 0.004 -inch brass liners and 60 -degree cone angles. Two of these were fired into silver targets and the third into a zinc target, all from stand-off distances of 12 inches.

A radiation survey meter (Technical Associates, Model F-1 with TA-G4 tube) was taken to the scene of firing and the charge, the target, and the backstop were carefully surveyed for any indications of radioactivity before firing. Immediately after the firings, the targets (or fragments in the case of the 6-inch charges) were checked for radioactivity. The targets and fragments were then brought into the laboratory, and a check for radioactivity was made with a more sensitive radiation detector (Radiation Counter Laboratories Model 100 Mark 1 Geiger tube).

Those targets which were subjected to the 2-inch charges were then sectioned through their craters ${ }^{4}$ and a section placed on a photographic plate, being insulated from it by a thin sheet of paper. In those cases where the targets were shattered, fragments were placed on the photographic plate. Those targets subjected to the 4-inch charges showed very little physical damage. Chips from the exposed surface of the silver and zinc were placed on photographic plates. The plates used were C.T.C. Pan and Kodak Spectroscopic Plates.

Contrary to what is reported in reference 1 , we found no evidence, either from the radiation counters or from the photographic plates, that any radioactivity was produced by the firing of the shaped charges.

1 Zygmunt Fonberg, J. Chem. Phys. 19, 383 (1951).
2 W. M. Evans and A. R. Ubbelohde, Research (London) 3, 376 (1950).

3 Birkhoff, MacDougall, Pugh, and Taylor, J. Appl, Phys, 19, $563(1948)$

4. M. Evans and A. R. Ubbelohde, Research (London) 3, 331 (1950), 